\title{
Social and Economic Impacts of Community Managed Reforestation and Natural Regeneration of Forestry Development, the Case of Humbo District, Ethiopia
}

\author{
Asamere Wolde ${ }^{1}$, Tadesse Amsalu ${ }^{1} \&$ Molla Mekonnen Alemu ${ }^{1}$ \\ 135 Frazer Street Wilkinson Road, Freetown, Sierra Leone \\ Correspondence: Asamere Wolde, 35 Frazer Street Wilkinson Road, Freetown, Sierra Leone. Tel: 232-7653-1728. \\ E-mail: asamerewol@yahoo.com
}

Received: September 6, 2016

Accepted: September 21, 2016

Online Published: October 17, 2016

doi:10.5539/enrr.v6n4p36

URL: http://dx.doi.org/10.5539/enrr.v6n4p36

\begin{abstract}
This study was undertaken in Humbo District, Ethiopia. The objective of this study is to assess the effects of reforestation initiatives on the socio-economy of the rural households brought by the existence of the Community Managed Natural Regeneration (CMNR) project. Four Kebeles (administration units in a district) were selected for the study, based on their geographical location. One Kebele Administration (KAs) from four corners (North, South, East and West) of the closure area was selected. A total of 203 households were involved in the survey. Data were generated through questionnaire, FGDs, KIIs, and physical observation. The study depicted that respondent households were participating in the designation process and subsequent management of the Humbo CMNR project which in fact is considered to be good indicator for its sustainability. They also have good perception on planting trees, reforestation programs and on the ownership of forests as well. It was noted that in some of the surveyed KAs, drought, water constraints and strong wind are the main challenges of the communities. There are available institutional setups and bylaws to manage and protect the forest which was formulated by many stakeholders including local communities. To mention some; bylaws workable for penalizing illegal intrusion into the closure, igniting fire on the forest and benefit sharing.
\end{abstract}

Keywords: Community, natural regeneration, reforestation, area closure, coping strategy, sustainability, institutional set ups

\section{Introduction}

Nowadays, forest resources are treated with a good attention because of people's perception on their direct and indirect benefits for the community in specific localities and for a nation in general. The benefits of reforesting a given area are expressed in terms of economic, social and environmental impacts. Economic benefits can be employment opportunities and increased income at household, community, country and global level in general. Institutional set ups emerging at local level for the protection and management of community based forest resources, active involvement of women and the youth can be considered as social benefits as they might lead to strong social capital development. The value of forests to the world's human population is becoming increasingly evident. All these incidents seem to have been taking place largely in the absence of any legal frameworks or by-laws on how to responsibly use and maintain the forest resources. Tree cutting and charcoal making are the livelihoods of last resort. They involve significant labor inputs for very little income and mainly people who have no other options for income generation would go for the activities like this. It is widely accepted that smallholder and community-based forestry development can help alleviate rural poverty (Tipper, 2002). Such interventions have the potential to be in a win- win situation (UNEP, 2002). Community-based reforestation programs though having great potential for local community development, they face many challenges as the poor record of accomplishment of such programs testifies. As Edward Wolf of World Watch Institute wrote in the foreword to Reforestation in Arid Lands (Warner K, 1997), "reforestation has become a centerpiece of rural development in arid lands, a key to conserving soil and water supplies, securing food production, and reducing the hardships of rural life', Farmer Managed Natural Regeneration (FMNR), however, is believed to be the systematic regeneration of this pre-existing " underground forest'". 
The Community Managed Natural Regeneration (CMNR) pilot project in Humbo involves the restoration of tree cover and biodiversity in a degraded mountainous part of Humbo Woreda/District of South Western Ethiopia. The CMNR project is intended to contribute to the local community livelihood by improving the quality of water, reducing soil loss, giving an opportunity for fodder and fuel wood collection thereby protecting cropland by controlling flood hazards and improving biodiversity of the area. The move to bring the Humbo forest under rehabilitation through active involvement of the community is envisaged to trap many local socioeconomic benefits and ecological stability. It is evident that improvements in the vegetation cover of Humbo forest are quite visible. However, despite the great interests to rehabilitate the Humbo degraded forest, efforts to generate data indicating what is really happening in Humbo forest in the context of the objectives of its establishment is limited. The knowledge gap in the overall management of Humbo forest makes it difficult to give a clear account of the state of the forest and more importantly, to substantiate the significance of initiating and implementing community based forestry development programs.

It should be noted that FMNR in one form or another is not new. In fact examples that are centuries old can be found in various parts of the world including Europe, Japan and Africa. There is anecdotal evidence from Niger and neighbouring countries that spontaneous "rediscovery" and organic spread of FMNR occurred within the same period as the SIM experience.22 Also in 2004, World Vision Australia and World Vision Ethiopia initiated a forestry-based carbon sequestration project as a potential means of stimulating community development while engaging in environmental restoration. An innovative partnership with the World Bank, the Humbo Communitybased Natural Regeneration Project involved the regeneration of 2,728 hectares of degraded native forests. This brought social, economic and ecological benefits to the participating communities. Within two years, communities were collecting wild fruits, firewood and fodder. They reported that wildlife had begun to return and erosion and flooding had been reduced. In addition, the communities are now receiving payments for the sale of carbon credits through the Clean Development Mechanism (CDM) of the Kyoto Protocl.23 24 Figures 3 and 4: Satellite photos taken in 1975 (left) and 2005 (right) show greatly increased tree cover in southern Niger. Trees show as black dots. Source: US Geological Survey Following the success of the Humbo project, FMNR spread to the Tigray region of northern Ethiopia where 20,000 hectares have been set aside for regeneration, including 10-hectare FMNR model sites for research and demonstration in each of 34 sub-districts (Rinaudo, 2012). In addition, the Government of Ethiopia has committed to reforest 15 million hectares of degraded land using FMNR as part of a climate change and renewable energy plan to become carbon neutral by 2025 (UNDP, 2012). In Talensi, northern Ghana, FMNR has commenced on over 500 hectares and new projects, initiated by World Vision, are introducing FMNR into three new districts (Weston, 2013). In the Kaffrine and Diourbelregions of Senegal, FMNR has spread across 62,000 hectares in five years (Rinaudo, 2012). World Vision is also promoting FMNR in southern African countries. Other examples exist of both independently promoted and spontaneous FMNR movements occurring. In Burkina Faso, for example, an increasing part of the country is being transformed into agroforestry parkland. And in Mali, ageing agroforestry parkland of about six million hectares is showing signs of regeneration (World Agroforestry Center, 2012).

\section{Research Problem}

This study aims to assess the socioeconomic benefits of reforestation as perceived by households and the community. In addition, government and non-government institutional supports are assessed to develop an insight on the sustainability of CMNR project. Most importantly, as community based forest development involves a cross section of a community with diverse needs, capabilities, interests and attitudes the study is expected to provide plausible ways out for the multitude of problems influencing the effectiveness and sustainability participatory forest development interventions. Assessment of the socioeconomic of the Humbo CMNR project is therefore intended to generate viable knowledge and information that will serve as an important feedback to profitably manage the rehabilitated forest resource. It is evident that there are several abandoned and degraded lands scattered in many parts of the country. Knowledge developed in this study site can serve as an important lesson in efforts to replicate similar forest rehabilitation schemes. Carrying out a critical analysis of the community based forestry development like the Humbo intervention will indeed enrich the knowledge base that is needed to facilitate participatory forest development interventions in general.

\section{Methodology}

\subsection{Description of the Study District}

Humbo District is one of the 12 Districts in Wolayita Administrative zone of the Southern Nations, Nationalities and Peoples Regional State (SNNP). The District is bordered by Kindo Kosha District in the east, Soddo Zuria District in the North and Boloso Bombe District in the south. The District is located $25 \mathrm{kms}$ from Zonal capital 
Soddo, $195 \mathrm{kms}$ from the regional state capital, Hawassa, and about $430 \mathrm{~km}$ from Addis Ababa. The geographic location of Humbo (Tebella) township lies between $6^{\circ} 46^{\circ} 48.47$ and $6^{\circ} 41^{\circ} 04.28 \mathrm{~N}$ and between $37^{\circ} 48^{\circ} 35.44$ and $37^{\circ} 55^{\circ \mathrm{c}} 14.51 \mathrm{E}$. The study site is about $435 \mathrm{kms}$ South of Addis Ababa, and about $200 \mathrm{kms}$ South-west of Awassa, the capital city for SNNP (World Vision International, 2006).

\subsection{Climate and Agro-Ecology of the District}

Topographically, the altitude of Humbo District extends from 1300 m.a.s.l. at Kolla (hot lowland) to 2400 meters above sea level (m.a.s.l.). Humbo District is part of the Great Rift Valley of Ethiopia and is sub divided in to 2 climatic zones, midland (Woina Dega) and lowland (Kolla). The Woina Dega consists of undulating rugged hills and plateaus while Kolla is relatively flat extending to Lake Abaya. The annual rainfall in the District ranges between 700 and $1000 \mathrm{~mm}$ with an irregular maximum record of as high as $2500 \mathrm{~mm}$ and many areas exhibit the symptoms of erosion and locally severe flooding. Rainfall variability in the study area has been reported as major problem in recent years. Temperature varies according to the season and elevation, and generally it ranges between 12 and $24^{\circ} \mathrm{C}$ with an average temperature of $18^{\circ} \mathrm{C}$ (Tino, 2007). The dominant soil types of the district include reddish soil and brown soil and others. The soil between Soddo and the Kenyan border varies between Nitosols, Lithosols, Fluvisols, Luvisols and Xerosols (EMA, 1988).

\subsection{Description of the CMNR Project Area}

The Humbo Community-Managed Reforestation and Natural Regeneration of forestry development project is located in Humbo district, some 5-10 kms southeast of Tebella town, the capital of the Humbo District, and lies surrounded by seven rural Kebele (Note 1) Administrations namely Abella Longena, Hobicha Badda, Bolla Wanche, Hoibicha Bongota, Abella Gefeta and Abella Shoya and having varying population and mean household size (Table 1).

Table 1. Rural Kebeles involved in the management of the Humbo community managed reforestation and natural regeneration project.

\begin{tabular}{llll}
\hline Kebele & Population size & Number HHs & Av. \# per HHs \\
\hline Abella Longena & 7006 & 1367 & 5.13 \\
Hobicha Badda & 4549 & 2115 & 2.15 \\
Bolla Wanche & 3883 & 554 & 7.01 \\
Bossa Wanche & 5042 & 1150 & 4.38 \\
Hobicha Bongota & 13538 & 2050 & 6.60 \\
Abella Gefeta & 5431 & 938 & 5.79 \\
Abella Shoya & 3668 & 456 & 8.04 \\
& $\mathbf{4 3 1 1 7}$ & $\mathbf{8 6 3 0}$ & $* \mathbf{5 . 6}$ \\
\hline
\end{tabular}

Source: CMNR/A/R Project records.

The forest enclosure has a total area of 2,728 ha. The topography of the forest site is characterized by massif mountain and chains of hills interspersed with small valleys, gullies, rocks and flat plains. Part of the forest land (about $35 \%$ ) lies in the lowland (Kolla) areas and about $65 \%$ in the mid altitude (Woina Dega) area (Figure 1).

The forest rehabilitation project is designated as a carbon sequestration project where its day-to-day management is entrusted to the local community living in the Seven Kebeles. The government is in charge for providing technical assistance and financial support from the fund secured from World Bank to facilitate the forest rehabilitation programme. Communities living in the seven Kebeles have established Forest Development and Protection Cooperatives (FDPCs) and membership is on voluntary basis. The cooperatives have formulated their forest management bylaws that should be observed by all members.

Soils in the project area have been identified as vertisols/nitosols, underlain with ancient Precambrian basement rocks in the plains and calcareous soils at the hills. These soil types are common in the Ethiopian Highlands with a nitosol / vertisol gradient often occurring between the higher/steeper areas and the lower flatter areas. Nitosols are highly erodible and often acidic. Over-clearing has led to significant soil erosion problems, with mudslides occurring on the site (Note 2).

The seven kebeles surrounding the forest rehabilitation project land holding size follows similar patterns in the worda and almost all practice settled agriculture producing crops commonly grown in the woreda. They also practice an old age agro-forestry and planting of trees along farm borders. Local communities living close to the 
forest project site have close attachment to woodland now demarcated as a reforestation project site. Traditionally they have used the woodland/forest as major source of fuel wood, farm tools, construction material, and source of fodder for livestock and there are some segments of the local community whose livelihood is predominantly dependent on sale of wood and charcoal gathered from the woodland (Deribe, 2006). Many springs that emerge from the woodland are the other vital natural resources benefiting the local community though many of them have now become intermittent and small in volume.

The forest rehabilitation site has once been covered with dense mixed broad-leaved tree species, shrubs, herbs and grasses of food, feed, and fodder. Some of the most important trees and shrubs species were Ficus sur, Terminalia ssp., Acacia ssp. Balanites aegiptica, Croton macrostachys, Grewia flavescens, Erythrina abyssinica, Olea africana, Dodonea viscosa, Oxytenthra abyssinica, Acacia senegal, Acacia abyssinica, Guizotia abyssinica, Urtica simensis, Brassica integrifolia, Pittosporum abyssinica, Asteracantha longifolia, Arundo donax, Commelina benghalensis, Eleusine jaegeri, snowdenia polystachya, Solanum tuberosum, Ricinus communis, Beta vulgaris, and Hyperrhenia rufa. Currently however due to severe deforestation and continuous illegal encroachment by the local community much of the woody vegetation cover is lost and few remnant trees and shrub species scattered here and there are observed. The severity of the forest degradation is exhibited by the indicator species like Dodonea viscosa, and Acacia dreanolobium which are already in the process of invading wider spaces in Humbo site (Deribe, 2006). As it is true elsewhere in the district the study kebeles face development constraints such as fragmented and small land holdings, poor soil fertility/soil erosion, dependence on rain fed crop production system, poor infrastructures such as access roads, clean water supply, lack of grazing land, lack of technical skills, etc. Though limited in scale and scope there are some development intervention being undertaken by the local government such as promoting soil and water conservation, small scale irrigation, provision of improved seed, tree seedlings, credit services, veterinary services, health extension support, construction of labor based access roads, opening of schools and heath posts, etc. In general there are efforts made by the government to mobilize the local community to be active partner in local development activities.

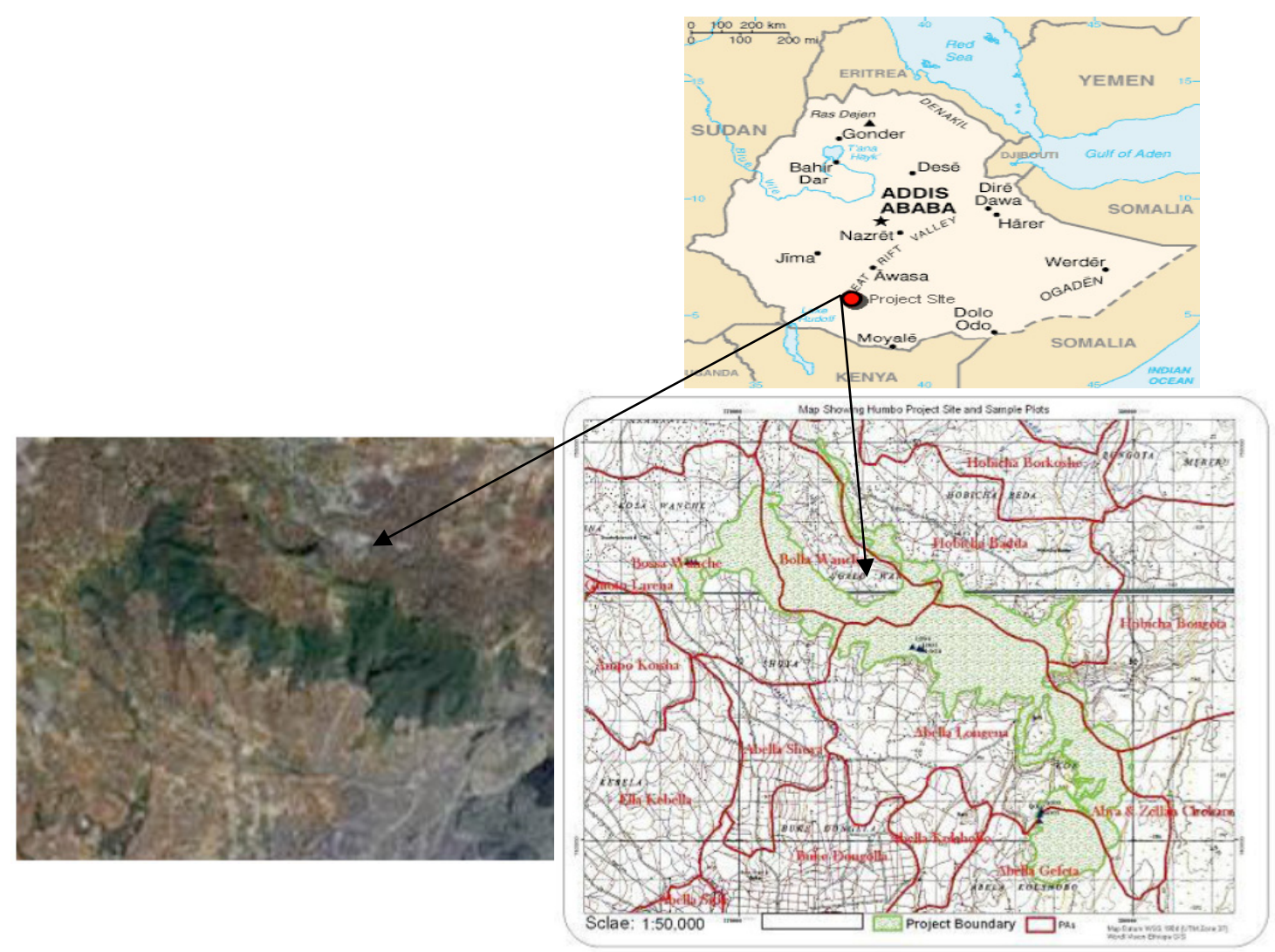

Figure 1. Map of the study area (Source: CMNR/A/R Project records) 


\subsection{Socio-Economic System of the District}

Population data of the 2007 national census shows that the woreda has a total population of 136,679 (CSA, 2007) of which the majority (92\%) are rural inhabitants. With an estimated area of 384,583ha, Humbo Woreda has a population density of 478 per $\mathrm{Km}^{2}$. The largest ethnic group in the district is reported to be Wolayita tribe (95\%). "Wolayitegna" language is spoken as a first language by $99.9 \%$ of the inhabitants. The majority of the population practice Ethiopian Orthodox Christianity with 99\%, while $1 \%$ are Muslims (CSA, 2007). Of the total land area of the Woreda, about $24 \%$ is coved with plantation and natural forest, $1 \%$ is grazing land, $66 \%$ agricultural land, $8 \%$ settlement, and others occupy $1 \%$ (Deribe, 2006).

Farmers of the district practice a mixed farming system, with crop and livestock husbandry being largely practiced in the traditional management system Information from the district agricultural development office shows that the major crops cultivated include maize, sorghum, sweet potato, Teff (Eragrostis teff), coffee, cotton, haricot beans and chickpeas while livestock predominantly include cattle, sheep and goats. Apart from farming some households practice off farm activities such as petty trade, handicrafts, and seasonal migration to supplement their livelihood incomes. Likewise there are also a number of households that are engaged in collection of fuel wood and making of charcoal from remnant woodlands to generate income for the family. Farm land holding in the district is small and it ranges from 0.125 to 2 ha and the average land holding per households is about 0.3 ha. There is high fragmentation of farmland; the average number of plots per household in the district is estimated at 3.56. Many households with small land holdings are reported to be facing food deficit. There are signs where the local farmers are encroaching into fragile ecosystems such as hillsides to cultivate crops and this coupled with overgrazing and complete removal of the woody vegetation seems to have played a big role the degradation of much of the steep slope areas in the district (Deribe, 2006).

\subsection{Sampling/Site Selection and Data Collection}

\subsubsection{Stratification of the Project Site}

To enhance the forest rehabilitation interventions the Humbo CMNR site was stratified into four strata based on vegetation cover, terrain, slope and altitude of the sites (Figure 2)

Stratum 1: Southernmost part of the project with few scattered trees. This area is the closest to Lake Abaya, and is at lower in elevation than the rest of the project strata.

Stratum 2: It is in two sites, a small site in the northern part of the project with the major part of the stratum lying between stratum 1 and stratum 3. It has scattered trees and grass cover and is the least undulating of the project strata.

Stratum 3: It has the largest area and accounts for about $40 \%$ of the project area. It has shrub growth and encompasses the southern sloping aspects.

Stratum 4: It is the northern most part of the project and has shrub vegetation on rocky hillsides, with a northerly aspect.

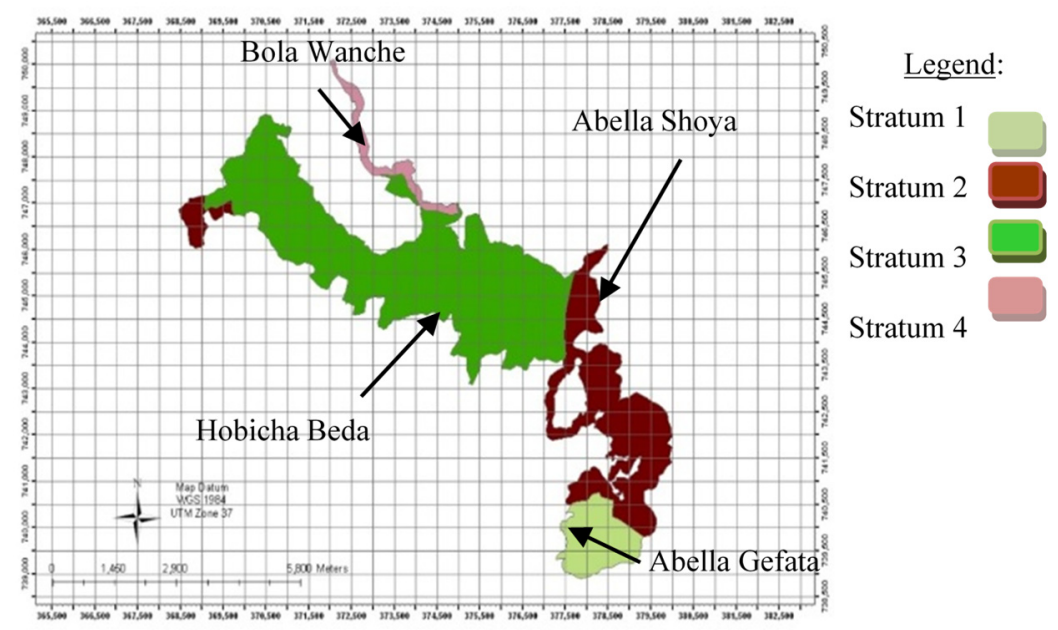

Figure 2. Map of the study area (Source: CMNR/A/R Project records) 


\subsubsection{Reconnaissance Survey}

The fieldwork for this study was carried out from February 2012 to March 2012. The initial field activity was a reconnaissance survey of the study area to establish background information on agro ecological condition, livelihood activities, land use systems, natural resource base, and development activities being implemented. Relevant interactions were also carried out with governmental and non-governmental institutions working in the district and at zonal level and selected individuals having knowledge of their localities were also met to obtain further information about the study area. This exercise in general has helped the researcher to establish a general picture of the proposed study area and prepare a relevant questionnaire and group discussions issues. The preliminary study of the assessment area was followed by study site selection.

\subsubsection{Study Site Selection}

Humbo CMNR project is aimed to bring socioeconomic development through environmental rehabilitation and the principal stakeholders in the management of the project are the seven Rural Kebeles bordering the reforestation site. In the process of selection of the specific kebeles for the study, consultation was carried out with the local agricultural development agents, and Kebele cooperatives established to facilitate the management of the development activity and criteria for sample kebele was established. Accordingly Kebeles having more households far from the reforestation site were grouped together; others with better access road and market (urban centre) were grouped in another category; and those Kebeles deemed facing more food insecurity were set aside as another category in the site selection process. Taking note of the above variables using purposive sampling method, four Kebele Administrations namely Hobicha Beda, Bola Wanche, Abela Shoya and Abela Gefeta distributed in different parts of the CMNR project were selected.

\subsubsection{Selection of Respondent Households}

The local communities residing around Humbo closure are used as the primary sources of information. Hence, representative households and community groups were selected from list of households in the four Kebeles that served as a sampling frame. The current Kebele Administration is structured to have many "gotts" or hamlet comprising substantial numbers of households. The number of gotts in each Kebele Administration was recorded and their relative position to the location of the Humbo CMNR project site was identified. In this exercise Hobicha, Keranso, Shoya, and Koisha gotts were recorded for in Hobicha Beda, Bola Wanche, Abela Shoya and Abela Gefeta kebeles respectively and a total of 12 sample gotts were taken proportionally. Households in each gott were then stratified in different wealth groups with the help of knowledgeable persons and development agents based on local value judgments accepted by the local community. In this respect livestock ownership, land holding, capability of producing adequate grain for the family were considered as major criteria for classification supported by close knowledge of the economic status of each household.

About $5 \%$ of the total beneficiaries out of the four Kebele administration were taken as a sample for analysis (Table 2). Taking into account that this research relies on multiple data sources and considering the ideas promoted by (Fritz Scheuren, 2004) that sample size was fixed at 5\% and a total of 203 households were used for the study.

Table 2. Sample Respondent households in the Study Kebeles/ Distribution of Sample Size per Kebele

\begin{tabular}{lllll}
\hline Kebele Name & Pop. & HH No. & $\mathbf{5 \%}$ of the HH & Ave. HH size \\
\hline Hobicha Beda & 4549 & 2115 & 106 & 2.15 \\
Bola Wanche & 3883 & 554 & 28 & 7.01 \\
Abela Shoya & 5431 & 938 & 46.9 & 5.79 \\
Abela Gefeta & 3668 & 456 & 23 & 8.04 \\
Total & $\mathbf{1 7 5 3 1}$ & $\mathbf{4 0 6 3}$ & $\mathbf{2 0 3}$ & $\mathbf{5 . 7}$ \\
\hline
\end{tabular}

After fixing the sample size for each study Kebele, the sample households of each Kebele were proportionally allocated to the three wealth status category (better-off, medium and poor) (Table 3); and sample households for each Kebele were selected by applying simple random sampling statistical technique and using the Table of random number. 
Table 3. Distribution of Sample Size by Wealth Status per Kebele

\begin{tabular}{|c|c|c|c|c|c|c|}
\hline \multirow{2}{*}{ Name of KAs and Total household in sample Gotts } & \multicolumn{3}{|c|}{ Wealth Status Across Gotts Selected in Each kebele } & \multicolumn{3}{|c|}{ Allocated Sample size } \\
\hline & Poor & Med & Rich & Poor & Med & Rich \\
\hline Hobicha Beda (5 gotts) & 75 & 54 & 40 & 44 & 31 & 29 \\
\hline Bola Wanche (2 gotts) & 29 & 33 & 41 & 8 & 9 & 13 \\
\hline Abela Shoya (2 gotts) & 21 & 31 & 30 & 6 & 9 & 8 \\
\hline Abela Gefeta (3 gotts) & 35 & 48 & 46 & 11 & 18 & 17 \\
\hline Total & 160 & 166 & 157 & 69 & 67 & 67 \\
\hline
\end{tabular}

\subsection{Data Collection Tools}

\subsubsection{Households Interviews}

To realize the objectives of the study, a questionnaire was designed to include a range of issues that could provide an insight into the socio-economic system of the household (demographic characteristics, livelihood activities, access to markets, extension support, etc), and their involvement in the CMNR project, their perception on the importance of the reforestation project, and institutional arrangements to run the project and other related issues. Both close and open-ended questions that address the specific objectives were included to explore the required data from the sampled HHs. The preparation of the questionnaire was preceded by reviewing of literature related to the preparation and analysis of survey questionnaire.

The questionnaire was then pretested on 12 households living close to the project area to make sure that the questions are relevant and easily understood by the interviewee and to improve the content of the questionnaire. Accordingly, some questions on quantifying the benefits were modified in qualitative forms. Redundant and unnecessary questions were also detected and removed, and difficult expressions were made clear.

Four data collectors, one for each sample Kebele, were used to complete the survey questionnaire. They were given training first to thoroughly understand the contentment of the questionnaire and secondly to give them skill on how to approach the respondents during the interview. In general the maximum possible effort was made to gain as much relevant information as possible from respondent households by giving due consideration to their demands on timing and place of the interview as well as carefully recording their responses.

\subsubsection{Focus Group Discussions}

Group interviews in the form of focus group discussions using semi structured questions gives researchers to have a better opportunity to look into more deeply into issues of concern and develop new lines of inquiry that arise during interviews (Gilham, 2000). Focus group discussion interviews were therefore conducted to supplement and substantiate information that was generated in the household questionnaire and in-depth interviews with key informants. In the group discussions, individuals and institutions familiar with the forestry development project were included. Accordingly, a total of 12 focus group discussions were held in the study Kebeles and the number of people participating in each group varied between 7 and 13. The focus group discussion involved members of the FDPC from the four Kebeles, men and women group of different asset endowments, one in each Kebele, Cabinet Members of the four Kebeles, and informal discussions were also held with school teachers and students.

A checklist of questions was prepared for each group. Issues addressed in the focus group include awareness on the importance of the forestry development, perception matters on ownership, intuitional arrangement, capacity building, sustainability of the forest resource being developed, etc. Likewise, group discussions were held with the staff of the District Agricultural Development Office and the Bilateral Organizations with the aim of generating information that will be useful for future management of the forestry intervention. Hence the discussion gave focus mainly on institutional matters pertaining to the management design of the reforestation project, arrangements of benefit sharing, capacity building made at local level and in the office, sustainability matters and major challenges or issues requiring immediate response, etc. All group discussions were held in a language that everyone speaks well and the researcher was assisted by a note taker who was oriented on how to document and organize the most important issues raised during the discussions.

\subsubsection{Interviews with Key Informants}

Key informant interviews were carried out by involving selected group of individuals who are likely to provide needed information, ideas, and insights on the proposed researches as argued by (Kumar, 1989). Key informants were selected with the help of the Kebele Administration and agricultural development agents. Three Key informants were used in each Kebele. Checklists of open-ended questions were prepared and used for the interview. 
The major topics discussed included information about the process of designating the CMNR project, perceived benefits from the project, ownership and sustainability issues, etc. The interview was conducted at the place and time convenient for the key informants. Key informant interviews were conducted in Amharic and recorded by hand written notes and by digital voice recorder. Digital voice recordings were then transcribed and documents were imported into MS-excel software for coding against the key research questions.

\subsubsection{Data Validation Process and Management}

Maximum efforts have been exerted to keep the quality and clarity of the household level data. Raw data was well cleaned and verified carefully on the field through supervising the collection process. It was rechecked in the office prior to encoding for its credibility and best results. An effort was also made to reduce defects before the fieldwork is completed if in case some errors and vague records observed. Every questionnaire was checked at the field after being completed by enumerators.

\subsubsection{Data Analysis}

In conducting this study, both qualitative and quantitative data were collected; hence, a combination of quantitative and qualitative data analysis methods was carried out. Data collected from focused group discussions were immediately summarized through discussion with an assistant note taker/enumerator. Outstanding and prominent issues rose during group discussion and key informant interviews were screened by checking how many of the speakers and which category of households have reiterated the same issue in the process of the discussion. Both diverging and converging issues on particular issues were identified and used for analysis in the context of the research objectives and questions.

Most of the variables collected in the questionnaire and used in the analysis were categorical, nominal or ordinal. In addition, the numeric or measurement variables were often not normally distributed. Hence, non-parametric tests Chi Square $\left(\mathrm{X}^{2}\right)$ tests was used in the analysis to see the association between independent variables (sets of household characteristics, villages and institutional variables) that are likely to influence local community involvement in the forestry development efforts and also perception matters on the overall management of the project. An association level of 0.05 was chosen as the minimum significance level. Depending on the relevance of data regression analysis was also carried out. The analytical tests were also in many places supported by descriptive statistics (such as computation of percentages of single variables, the median and average outcomes) and prominent views gained during focus group discussions. The latest SPSS-statistical software was used for analysis.

\section{Results and Discussions}

This chapter presents the results and discussion of the study. It describes the demographic characteristics and socioeconomic activities of the respondent households in the context of the research. And then discuss about perception and attitudinal matters related to the reforestation project, capacity developed and finally it addresses institutional issues influencing the involvement of beneficiary households and effectiveness and sustainability of the forestry development program.

\subsection{Gender Mix and Age of Respondent Households}

The sample households interviewed in this assessment are totally 203 of which $148(72.9 \%)$ are male and 55 (27.1\%) are female. The households represented in the study encompassed age groups of 30 and above. As explained in Table 4, about $67 \%$ of the household heads are between 30 and 50 years of age, while those aged between 51 and 60 years accounted for only $26.6 \%$. The least share (4.4\%) is represented by household heads over the age of 61 . The predominance of a reproductive population in the study area implies that population density is increasing at a very fast rate and may pose stress on the environment. Hence, it seems logical to strengthen family planning activities already in place in the district albeit in limited extent. On the positive side, mobilizing this potential immense work force for productive activities can bring tremendous development.

The average household size of the study population is 6.5 with a range of 3-10 household members within a family. Although the age distribution is not worked out, the household size is an indicator of labor availability within the household. Literature indicates that households with more family members are most of the time expected to spend part of their time for tree growing and other activities related to forest management. However, there is a fact that the more the family size will result in increased need of the household to feed them all. In pursuit of meeting the family's need, there could be kind of encroachment on the closure particularly by economically weak segments of the community and this was particularly witnessed by group discussion participants stating that poor households still tend to encroach the Humbo community managed natural regeneration site. 
The participation on forest management and protection activities differs between male and female respondents. Male household heads do most of the forest protection works though there was some involvement from female household heads. This is one of the areas the institutions that have stake in management of the closure should work further so as to bring about a good gender balance. Based on the assessment result, it can be said that some woman have been participating in trainings conducted by the CMNR project stakeholders ever since the start. All of the respondents stated that women participation in the CMNR project had meaning so as to enable it sustainable. It was noted that there is an association between age of individuals and involvement in the management of forest $\left(\mathrm{X}^{2}=8.275\right.$ and $\left.\mathrm{df}=6, \mathrm{p}<0.05\right)$.

\subsection{Wealth Status and Level of Engagement on Forest Encroachment}

All groups of people (poor, medium and better off) have nearly equal contribution to works that should be done by them as a requirement. Sometimes the works of those people categorized under medium weighs a bit more. Pruning is one of the main activities undertaken by most of the respondents; about 87 (42.9\%) out of the total $(\mathrm{n}=203)$. Out of which, about 41 respondent households were medium, about 23 respondents were poor households and the rest 23 of them were found to be better-off. Hoeing is also another main activities identified to be practiced by all class of people. Out of the 68 households who were undertaking hoeing, about 26 of them were poor households, about 25 respondents were better-off and the rest 17 respondents were medium class households. The surveyed households according to the findings have found to be less practicing wild life conservation and weeding. Despite the fact that these activities are less practiced, about 31 respondent households have said that they were involved in wild life conservation works. Out of them, about 13 were poor households, 12 were better-off and about 6 were medium class households. Only 17 of the total respondents $(\mathrm{n}=203)$ had stake in weeding. Out of the 17 households, about 7 of them were poor households, again 7 were better-off and the rest 3 were found to be medium class households.

Table 4. Kinds of work distribution among female and male headed HHs

\begin{tabular}{|c|c|c|c|c|c|}
\hline \multirow{2}{*}{ Sex of the HH } & \multicolumn{4}{|c|}{ Kind of work HH undertakes } & \multirow{2}{*}{ Total } \\
\hline & Weeding & Hoeing & Pruning & Wildlife conservation & \\
\hline \multirow[t]{2}{*}{ Male } & 12 & 55 & 57 & 24 & 148 \\
\hline & $8.1 \%$ & $37.2 \%$ & $38.5 \%$ & $16.2 \%$ & 100 \\
\hline \multirow[t]{2}{*}{ Female } & 5 & 13 & 30 & 7 & 55 \\
\hline & $9.1 \%$ & $23.6 \%$ & $54.5 \%$ & $12.7 \%$ & 100 \\
\hline \multirow[t]{2}{*}{ Total } & 17 & 68 & 87 & 31 & 203 \\
\hline & $8.4 \%$ & $33.5 \%$ & $42.9 \%$ & $15.3 \%$ & 100 \\
\hline
\end{tabular}

Increased involvement of people in forests through community-based management programs has in many cases proven to benefit the environment (soil erosion reduction, water supply and biological diversity) and reducing local poverty (Salim, 1999). In this study, the reasons for growing trees as revealed by respondent households are related to environmental concerns in the first place followed by firewood needs, generating cash income, collection of construction wood, and production of fodder. Tree planting, contribute to conservation of biological diversity, both at the site and landscape level, extensive reforestation with plantation species can help ameliorate long-term environmental degradation in badly eroded landscapes, restoring not only ecological functionality but also site productivity (Maginnis and Jackson, 2003).

\subsection{Major Livelihood of the Community}

The livelihood of the local community is primarily dependent up on agriculture with some exercises in petty trade for supplementing their household need (Table 5). Crop production is one of the activities commonly practiced in the area for assisting livelihood of local communities. However, it is currently constrained with several shortcomings. The first constraint in crop production according to households' in-group discussion is lack of access to improved agricultural technologies including commercial fertilizers, pesticides and improved seed. Another severe obstacle is small land holding and landlessness. About $90 \%$ of the respondents disclosed that there are many young people looking for land but were not able to have access to land holdings due to shortage of arable land. 
Table 5. Major Livelihood of local community

\begin{tabular}{lll}
\hline Activities & Frequency & Percent \\
\hline Agriculture and Petty Trade & 106 & 52.2 \\
Agriculture & 97 & 47.8 \\
Total & 203 & 100.0 \\
\hline
\end{tabular}

The area is known for its high population pressure and hence shortage of arable land is the main problem associated with agricultural production. Out of the total respondent households $(\mathrm{n}=203)$, about $117(57.6 \%)$ of them have a land size of 0.5 to 1 ha, some $39 \%$ hold 1 to 1.5 ha of land, only $2 \%$ and $0.5 \%$ of the respondent households own more than 1.5 ha and less than 0.5 ha of land respectively. The study also noted that the Humbo CMNR project did not displace households from their land holdings and their land holding sizes remained the same even after the area came under closure. The majority of households (66\%) in the study area feel that their land holdings are small and are barely adequate to satisfy their subsistence needs. About $34 \%$ of the households claim that they have adequate land and are able to produce enough food for household consumption and for the market as well. During group discussions, many of the participants stressed that there are many young people who are landless and may be a potential danger to the forest under rehabilitation. Unless the project integrates the demands of this segment of the community it eventually become difficult to control encroachment problems into the woodland.

\subsection{Benefits Obtained from the Closure}

The CMNR project document stated in its base line survey that the community will have a benefit to collect grasses, dried leaves and woods, medicinal plants, spices and wild honey. In addition to this, the local community is privileged to use the employment opportunity created as a result of the CMNR project (World Vision International, 2007). It is quite visible that closures if properly managed have wide range of benefits. In Humbo CMNR project case, the existing income source, which was only focusing on primitive agriculture, is believed to be replaced by the employment opportunity brought by the existence of the project and by trade of carbon offsets as well. The change is believed to come because of the awareness created after the closure is being kept by involving stakeholders thereby conducting several types of trainings for the community as most of the surveyed households reflected in this regard.

In addition, there are four types of benefit which are realized as a result of the existence of the forest resources management project. Harvesting dried leaves, barks and grasses from the enclosure is first ranked benefit as witnessed by $103(50.7 \%)$ respondents out of the total sample households $(\mathrm{n}=203)$. According to the household survey, about $64(31.5 \%)$ of respondents have said that Fuel wood (dried ones only) is another type of benefit, reduced flood damage and fruit/NTFPs collection are also the benefits as explained by 36 (17.6\%) respondent households and they are ranked as the second, third and fourth ranked benefits respectively. These resources are allowable only through contacting the cooperatives, which have been given main role in managing and protecting the forest. About $62 \%$ of the respondent households who are living near the closure have said that they are more accessed for most of the benefits shown on the figure 9 and the remaining $38 \%$ of the households who live far from the closure said that they have little access because of the distance between the closure and their settlement. Although there are benefits, there are also problems and challenges faced by the households who are closer to the CMNR site mainly because of wild life attack.

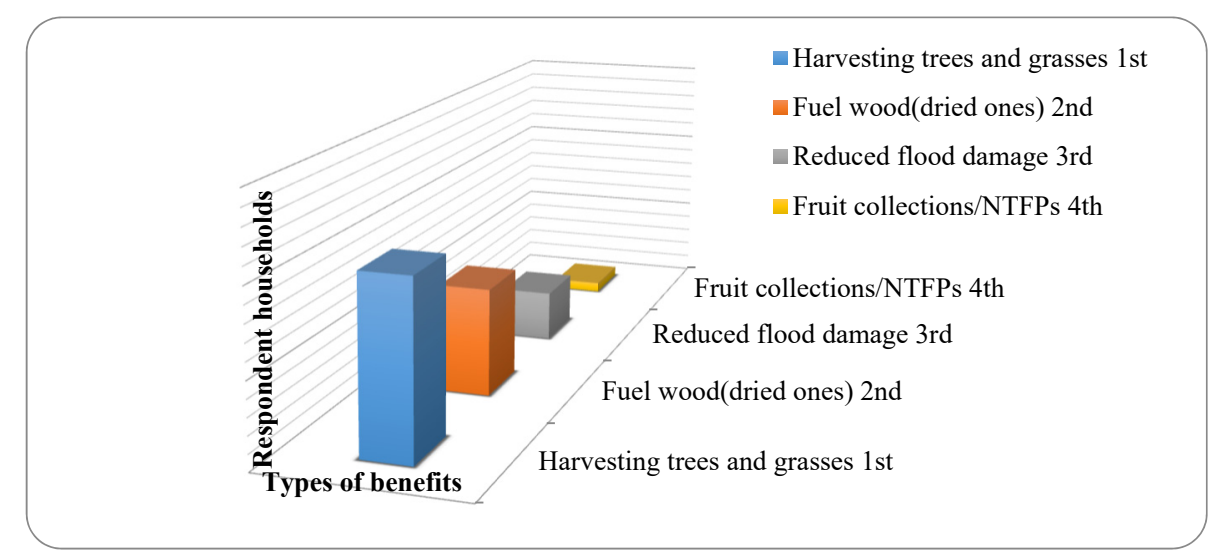

Figure 3. Types of benefits gained by the existence of the project 


\subsection{Employment Opportunities}

The information found with regard to income generation and creating employment opportunity had been triangulated by using the data gathered in FGDs, key informants and household survey. Food insecurity has been a long-standing issue in the Humbo Woreda. A comment by a female community member during a FGD explained as follows:

"Keeping children nourished was a priority and in times of shortage of food, meals taken by adults per day were reduced. We use our food to feed the children, and we go to sleep without eating"

Most households are food secured between September and November. Then the proportion of households that are food secured declines rapidly over the following five months and virtually no households are food secured by April. This is the experience of poor and middle class communities as findings from the household survey depicted. As the trends for household within the CMNR project area shows, during the peak food-shortage months (December to May), households in the project area seem to be working off farm activities in a slightly better manner. This may reflect some change due to the project intervention. This is possibly due to increased access to income from sale of wood and grasses, or to decreased expenditure on forage and firewood at the household level, due to access to wood and grasses in the protected area. Only members of FDPCs have access to the protected area to collect firewood from pruning and harvest dried grasses.

\subsection{Income Generated at Household and Community Level}

The protection and regeneration of the Humbo forest through the CMNR project has effected many positive changes in the surrounding microclimate, and members of the FDPCs were sustainably harvesting firewood and grasses - thus reducing expenditure on these items at the household level, or earning small amounts of income through sale of these items. However, the scale of savings or income earned was modest and would also provide a limited buffer from food shortages at the household level.

"[Humbo] protected area is improving, there is more rain and temperatures is going down, and we use the pruned wood from the protected area to sell at market" [Women FDPC member, Humbo, February 2012].

"There is some evidence that communities were diversifying their livelihoods to include trees for economic return and for improved food security. The main tree types owned (Eucalyptus, Cordia, Grevillea, Mango, Moringa and Coffee) are productive species. Apiculture is forest friendly and it has great potential in the future, communities have asked us to point out where they can buy the materials, it is a forest friendly activity. It has potential in the market. It can even be exported as an organic product" [WVE Project Officer, February 2012].

Assessing the income created by the project existence was started by interviewing one of the KI from the CMNR project staff at National Office level. It is stated as follows;

"Humbo is the first CDM project registered in Ethiopia so the EPA is proud of this achievement. We thank God! We are also very satisfied with the progress of the project, with the objectives being met so far, including the creation of jobs, the restoration of the environment, the flooding has stopped, preventing the stones washing down on the fields. A key achievement expected is that funds will go to the community through sale of carbon Certified Emission Reduction (CER). It means a lot and there is even some money being flow down to the communities"

A key component of the Humbo CMNR project model is the provision of income from carbon. The potential for communities to receive income from the sequestration of carbon as their communal forest regenerates makes this project a 'first of its kind' for the country. As studies show, clean development mechanism (CDM) projects range from the purely commercial, aimed at generating returns to investors, through to those whose goal is to increase the incomes of local landowners by using carbon markets as a component of a rural development strategy (Jindal et al., 2008). 
The carbon-trade registration process with World Bank extended for over the years, understandably testing the patience of communities and other stakeholders in the process. Feedback from community members also highlighted ambitious plans for development outcomes from carbon funds. This is explained by Women FDPC member;

"Food, water and wood are the major identified problems in the Woreda. I expect water development works from the carbon project. In future, we want to see a factory, a store for crops to conserve grain. If we get carbon money, we can buy oxen for those who do not have it. Water needs more development. We need a vehicle to serve the community as an ambulance"

And Male community elder;

"We hope we will be benefiting even more from this project, especially from the carbon credit; we have plans to construct a health centre and roads because of this project"

Community respondents' expectations from carbon revenue included expensive interventions such as provision of better infrastructure and services for health and education, and income generating activities such as eco-tourism. The extent to which these expectations can be met depend on a number of factors, such as the ability of community to meet monitoring and reporting requirements, collectively manage carbon funds, the price of carbon, management and protection of forest from illicit use and natural disasters such as bushfires and prolonged drought.

According to the emissions reduction purchase agreement with the WB, Income from Carbon revenue $\left(1^{\text {st }}\right.$ round payment 34,184USD/ 579,029 Ethiopian Birr (ETB) transferred to community on 15 March 2011). Some Kebeles have more population with large hectare of protected land than others and hence receive a larger share (World Vision International, 2012). Though the share seemed like this, the money will not be directly handed over to the individuals. Because they have agreed to use the income gained by sale of carbon to be invested on development schemes like; building grain store, bridge maintenance, and purchase of mill-grain etc. As a result of which, the communities had shown enthusiasm towards sustaining the CMNR project.

\subsection{Energy Sources for Household Consumption}

The main energy sources for household consumption were identified to be fuel wood, crop residue and cow dung as explained by the respondent households with a percent proportion of $69 \%, 18 \%$ and 13\% respectively (Figure 4) Fuel wood is mostly produced from the trees planted in their homestead and sometimes coop members can collect dried fuel wood from the closure. As the experience of the local communities depicts, they were solely dependent on the fuel wood that is produced from the communal forest over the years. Now, these practices somehow are being changed as a result of the project. The project not only has the physical work components but also it has a full package in order to address the public awareness by conducting various types of trainings with regard to managing and protecting the forest they own in their locality.

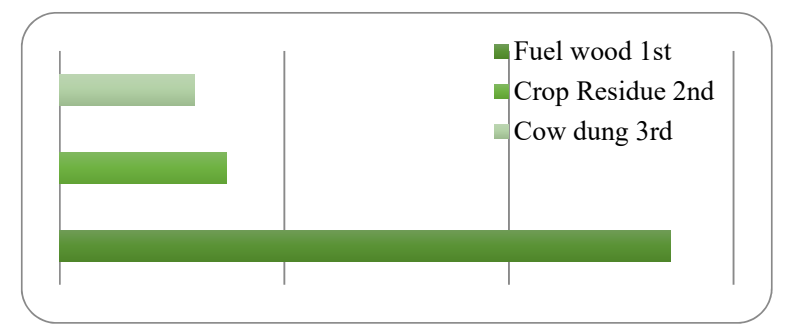

Figure 4. Energy source for $\mathrm{HH}$ consumptions

\section{Conclusions}

The community managed natural regeneration (CMNR) project to date has been implemented largely as planned with high levels of participation and strong ownership demonstrated by community and government partners. Feedback from respondent households and key informants highlighted genuine attitudinal changes in Humbo community towards trees and the forest, now seen as highly valued natural resources worth protecting. The change in the forested area in just three years is dramatic, with previously denuded slopes now blanketed in a cover of 
young trees, shrubs and grasses. The progress at Humbo demonstrates that communal forest protection combined with natural regeneration techniques (CMNR) and reforestation (tree planting) can produce remarkable, positive outcomes within a very short period. However, these considerable achievements were not without a struggle. Many community members stood to lose by locking up an area of land that had been freely accessible, and advocates of the CMNR project faced opposition and serious risks. Key informants during the study admitted that they were planning to attack those who were promoting the CMNR project. Then witnessing the return of the forest and associated benefits, they now state openly that their earlier judgments were very wrong. Future CMNR project planners need to learn from the Humbo experience; withdrawal of rights to access a communal resource is bound to meet with fierce opposition from those affected. The approach used by government was strategic and empowering; partnering with government to increase the legitimacy of forest protection, and enabling community to identify and determine the compensation for disadvantaged households.

The overall response to the project has been very good, as evidenced by growing memberships in the Forest Development and Protection Cooperatives (FDPCs). According to secondary data, there were over 4200 members in total - and based on a rule of membership, one member per household, this represents coverage of about $50 \%$ of the 8630 households across the seven Kebeles. The majority of respondents said they practiced CMNR technique on both communal and on their own farmland. Therefore, at this stage, there is growing evidence that project impact has gone beyond increasing awareness and building capacity, to actual practice change. The study found reliable evidence that the project approach has encompassed key stakeholder knowledge and participation in project design, implementation and management. Community feedback consistently showed genuine ownership of the project and advocacy for continued protection of the forest. Prior to closure of the forest, those households who would be negatively impacted were identified to be directly benefited by the CMNR through support for alternative livelihoods development. Women carry out many agricultural and forestry related activities and are a key target for projects attempting practice change, yet they are usually under-represented in such types of forestry. Under the FDPC membership rules, those who joined up at the start paid a low fee for membership, and then the membership fee increased over time. This would reflect the reduced investment in cooperative and forest management activities by those who joined later compared with the founding members. There was apprehension about the timing of the carbon benefits among community key informants, which suggests that there is work to be done by the CMNR to ensure that the associated processes and decision making includes the community and their partners. The Humbo model has since emerged as a key learning opportunity for Ethiopia and elsewhere in Africa. Moreover, it has also been showcased by the Ethiopian government, the World Bank and WV. Humbo FDPCs, WVE and the Ethiopian government are in a collaborative relationship with a shared goal for sustainable environmental and community development outcomes. It is believed to be effected through the protection of the Humbo forest. The carbon component has underpinned this high level of engagement and commitment, but in addition, the reputation of an organization like the World Bank and the now international profile of the Humbo CMNR has increased community confidence and led to a sense of pride and optimism.

\section{Recommendations}

- Create an agreed set of indicators, timeframes, and recording templates to enable local stakeholders to collect monitoring data required by WB. Ensure all stakeholders have the capacity and resources required to implement it.

- High profile of the project means there will be many visitors, and they need to plan for this. A protocol is highly recommended to be developed for hosting visitors. This should include agreement between local stakeholders about coordination of visits, visiting fees, role of community members as guides, facilitators required, production of brochures, etc.

- Create a project coordination committee at Humbo Woreda (District) level to coordinate CMNR activities locally and to facilitate communication between external stakeholders, local government and the Union formed by the FDPCs.

- Increased focus on equity of CMNR outcomes for women and poorest households.

- The multiple realities of the various CMNR partner's activities need to be assessed and revisited from time to time. The best way to do this is through face-to-face engagement.

- Take account of financial recording, monitoring environment, identify recurrent problems and set solutions.

\section{Acknowledgement}

Most of all, I would like to express my heartfelt gratitude to my supervisor Dr. Tadesse Amsalu, for his continuous and unreserved coaching and follow-up starting from the inception until the end of study period. If there was not 
his material as well as moral assistance, it would have been very difficult to overcome the challenges I faced during the whole course of the study. Molla Alemu Mekonen ( $\mathrm{hb}$ Candidate) has been a vital support and source of encouragement throughout the whole process of putting this article on publishing - my heartfelt gratitude goes to him as well. I am also indebted to Dr. Belayneh Ayele who not only stimulated my interest in this study subject but also assisted me in the planning process, generously sharing his wealth of experience.

I would also like to express my deepest respect to Ato Biyazen for his cooperation in laying out statistical analysis tools so that I could be much comfortable to work on my row data. I would also like to thank Ato Hailu Tefera for his cooperation during proposal development. The input from W/t Tsehay Ataklt is also highly appreciated. I would like to thank Bahir Dar University for giving me this chance. I also need to thank World Vision Ethiopia for assisting me with research finance. The kind cooperation of Elmi Nuri, Kebede, Kibret, Sintayehu Kefato and Sertsebirhan Hailu (Project staff), has been indispensable throughout my study time. I would like to extend my gratitude to Petros Alem, Dereje Mekonen, Ayana, Getahun Asnake and Dereje Mekuria (drivers of WV) for their unreserved collaboration. Finally, I would love to express my deep inside appreciation for my whole family who had always been encouraging me.

Special thanks also go to the farmers of the study area, for sharing their wealth of knowledge and resources for the accomplishment of this research. I also thank you all who have been encouraging me ever since I have started my works in the field until I finish my works; I really thank you once again!

\section{References}

Deribe, B. (2006). Humbo Community Managed Natural Regeneration Project Final Report, Addis Ababa (pp. 13-29).

FAO (Food and agriculture Organization). (1978). Community Forestry for Local Community Development. FAO Forestry Paper, Rome, 7(114).

FAO (Food and agriculture Organization). (2005a). The state of the world's forests (pp. 20-95). Food and Agriculture Organization of the United Nations, Rome, Italy.

FAO (Food and Agriculture Organization). (2005b). The importance of soil organic matter: Key to drought-resistant soil and sustainable food and production, Soils Bulletin. 80.

FAO (Food and Agriculture Organization). (2007). State of the world's forests. Food and Agriculture Organization of the United Nations, Rome, Italy.

Framework Convention on Climate Change - Secretariat. (2011). Executive Board of the Clean Development Mechanism. Meeting Report. 65.

Fritz, S. (2004). Qualitative Research Methods: Qualitative Survey sample size determination, Texas, 9-10.

Jindal R., Swallow, B., \& Kerr, J. (2008). Forestry-based carbon sequestration projects in Africa: potential benefits and challenges. Natural Resources Forum.

Kumar, K. (1989). Conducting Key Informant Interviews in developing countries. AID program design and evaluation methodology report. Agency for international development (AID), Washington D.C. 13(37).

Maginnis, S., \& Jackson, W. (2003). The pole of planted forests in forest landscape restoration UNFF inter-sessional experts meeting on the role of planted forests in sustainable forest management. New Zealand. 88-96.

Reij, C. (2012). African Re-greening Initiatives Blog. Retrieved from http:// www.africa-regreening.blogspot.com.au.

Salim, E. (1999). Our forests our future: Summary report of the world commission on forest and sustainable development. Manitoba, Canada. 6-34.

Tino, R. (2007). Forest Fire Management Plan. Humbo Assisted Community Managed Natural Regeneration Project, World Vision Australia.

Tipper, R. (2002). Helping indigenous farmers to participate in the international market for carbon services: the case of Scolel Te. In S. Pagiola, J. Bishop, \& N. Landell-Mills (Eds.), Selling forest environmental services: market-based mechanisms for conservation and development. Earth scan, London

UNDP. (2012). Programme document for Ethiopia (2012-2015). Retrieved from http://www.et.undp.org/content/ dam/ethiopia/docs/Ethiopia\%20Country\%20Programme\%20Document\%202012\%202015\%20-\%20English .pdf. 
United Nations Framework Convention on Climate Change. (2011). Subsidiary Body for Scientific and Technological Advice. Thirty-fifth session Durban.

Warner, K. (1997). The Vision and Role of Community Forestry in Sustainable Development. Proceedings of the XI World Forestry Congress. Social Dimension of Forestry's Contribution to Sustainable Development, 5, 57-68.

Weston, P., Hong, R., \& Morrison, V. (2013). Talensi FMNR Project: Endof-Phase Evaluation Report. unpublished, World Vision Australia/World Vision Ghana.

World Agroforestry Center. (2012). Improving Sustainable Productivity in Farming Systems and Enhanced Livelihoods through Adoption of Evergreen Agriculture in Eastern Africa, Research Proposal to the Australian Centre for International Agricultural Research, World Agroforestry Center, Nairobi

World Vision International. (2007). Natural disasters: World Vision responds to regional crises across the globe. Retrieved from http://www.worldvision.org/news.nsf/news/200709_natural_disasters?OpenDocument

World Vision International. (2012). Ethiopia. Retrieved from http://wvafrica.org/index.php, Option=com_content $\&$ view $=$ article\&id $=137 \&$ Itemid $=68$. Accessed Dec July 2011

\section{Notes}

Note 1. Kebele is an Amharic word that has a meaning of Chiefdom

Note 2. See fao.org/Wairdocs/ILRI/x5493E/x5493e19.htm

\section{Copyrights}

Copyright for this article is retained by the author(s), with first publication rights granted to the journal.

This is an open-access article distributed under the terms and conditions of the Creative Commons Attribution license (http://creativecommons.org/licenses/by/4.0/). 